\title{
SOFTWARE DIDÁTICO PARA CÁLCULOS DE SISTEMAS DE RECALQUE DE ÁGUA
}

\author{
Alexandre Rodrigues Chagas Silva ${ }^{1}$, André Luiz Justi², Paula Mayumi Saizaki ${ }^{3}$
}

\section{RESUMO}

Os cálculos necessários para determinar com precisão a perda de carga nos mais variados tipos de tubulações e acessórios que compõem um sistema de recalque de fluídos são longos, trabalhosos e suscetíveis a erros. Assim, o objetivo deste trabalho foi desenvolver um software didático para dimensionamento de sistemas de recalque hidráulico com aplicações na engenharia agrícola, todas páginas e componentes do software foram desenvolvidos através do ambiente de desenvolvimento integrado Lazarus 1.6 na linguagem de programação Object Pascal, o que possibilitou simplicidade no visual gráfico e robustez nos cálculos realizados, obedecendo às restrições indicadas na literatura para as equações adotadas, possibilitando assim, resultados confiáveis e com rapidez.

Palavras-chave: potência, motor elétrico, motor a combustão.

\section{ABSTRACT \\ DIDACTIC SOFTWARE FOR CALCULATIONS OF WATER RECESS SYSTEMS}

The calculations required to accurately determine the pressure drop in all types of pipes and fittings that make up a fluid discharge system are time consuming, laborious, and error-prone. The objective of this study was to develop an educational software to scale hydraulic systems with applications in agricultural engineering. All of the interfaces and software components were developed using Lazarus 1.6 in the Object Pascal programming language, which enabled simplicity in the graphical interface and robustness in the calculations, sticking to the restrictions adopted equations, thus obtaining reliable results quickly.

Keywords: power, electric engine, combustion engine.

\section{Recebido para publicação em 21/09/2016. Aprovado em 28/11/2016.}

1 - Acadêmico do Curso de Engenharia Agrícola da Universidade Federal do Paraná - e-mail: alexandrerodrigues@ufpr.br

2 - Docente do Curso de Engenharia Agrícola da Universidade Federal do Paraná -e-mail: aljusti@ufpr.br

3 -Doutoranda do Programa de Pós-Graduação em Eng. Química da Univ. Estadual de Maringá, e-mail: paula.saizaki@gmail.com 


\section{INTRODUÇ̃̃O}

Os avanços científicos e tecnológicos nas áreas de Sistemas de Informação e Engenharia têm automatizado tarefas que já foram manuais, e facilitado a resolução de problemas do meio agrícola, principalmente na criação de soluções acessíveis a pessoas que trabalham no campo. Dessa forma, observa-se uma tendência de inserção da informática no meio agrícola eaumento nos investimentos ligados a ela (BORBA, 2004). SANTOS (2011) afirma que o sistema Lazarus é um ambiente de desenvolvimento de aplicativos que possui um conjunto abrangente de opções e configurações, as quais o desenvolvedor pode utilizar para criar sistemas intuitivos para o usuário final, podendo também dar dicas de como deve ser utilizado em cada parte da inserção dos dados no sistema, alterando apenas as "hints" (propriedade responsável por mostrar dicas quando um determinado evento for cumprido).

A exibição de informações pertinentes durante a execução do programa pode auxiliar no entendimento das entradas, saídas (resultados e estimativas) e da parte técnica envolvida, resolvendo, assim, eventuais dúvidas sobre a utilização da própria interface (ZANETTI et al., 2005). No software, tal função fica a cargo das dicas ou "hints", que possibilitam a verificação de inúmeras condições simultâneas, proporcionando, então, a correta utilização dos cálculos indicados na literatura, deixando para o usuário a tarefa de apenas inserir os dados requeridos para qualquer propósito pré-definido e indicado nos formulários, que são as páginas do programa.

A aplicação de softwares no controle operacional da maquinaria agrícola não deve ser vista apenas como forma de eliminar problemas nas operações, mas sim com a finalidade de oferecer uma ferramenta de qualidade, que traz benefícios ao controle dos custos operacionais executados em uma propriedade agrícola. Entretanto, existe uma carência no setor de ferramentas que auxiliem no controle de operações agrícolas, especialmente aquelas relacionadas à tecnologia de informação (PIACENTINI et al., 2012). Tendo em vista essa necessidade de ferramentas computacionais na Engenharia Agrícola, o objetivo deste trabalho foi desenvolver um software didático para o projeto de sistemas de recalque hidráulico, com interface simples, visando atender requisitos presentes na literatura, mostrando-os ao usuário, além de servir como ferramenta de estudos e realização de cálculos.

\section{MATERIAIS E MÉTODOS}

O sistema foi desenvolvido na Universidade Federal do Paraná - UFPR, Campus Avançado em Jandaia do Sul em Linguagem Object Pascal, com o ambiente de desenvolvimento integrado Lazarus, executado no sistema operacional Microsoft Windows 8.1. Foram utilizadas imagens tratadas no software de edição de imagens GIMP 2.8, no sistema operacional Linux Mint, bem como componentes adicionais no próprio Lazarus, são eles: O LazReport (componente que permite a geração de relatórios em tempo de execução do software) e PowerPDF (componente que permite a geração de relatórios em PDF).

Para a construção do software de dimensionamento de sistemas de recalque, sistemas secundários foram desenvolvidos e adicionados ao projeto.

Como parte crucial do programa, foi desenvolvida a comunicação entre sistemas menores, que foram usados para gerar uma interface amigável, sem comprometer todas as regras e restrições das equações utilizadas e, além disso, permitir o acesso a dicas e ferramentas para auxiliar nas tomadas de decisões necessárias durante a sua execução e, também, poder verificar a comparação entre algumas equações hidráulicas.

O sistema principal, que realiza os cálculos, foi desenvolvido para seguir a sequência lógica das equações/dimensionamento, para isso, foram utilizadas variáveis em tempo de projeto para guardar dados até serem usados ou exibidos.

\section{RESULTADOS E DISCUSSÃO}

Para VALENTE et al. (2012), a construção de uma interface gráfica facilita o entendimento e utilização de um software e, com esse intento, foram criadas interfaces, tendo como ponto de partida a Página Inicial do software (Figura 1), onde existem menus na parte superior esquerda, que fornecem acesso às ferramentas de auxílio. Já na parte central, foram usadas 3 imagens que representam, em sequência, a identidade visual da Universidade Federal do Paraná, do curso de Engenharia Agrícola -UFPR e do Campus Jandaia do Sul-UFPR. Também na parte central foi posicionado o botão "Iniciar". Ao clicar nesse botão, o sistema de dimensionamento de recalque hidráulico é iniciado, bem como todos os processos que culminam no relatório final gerado pelo programa. 


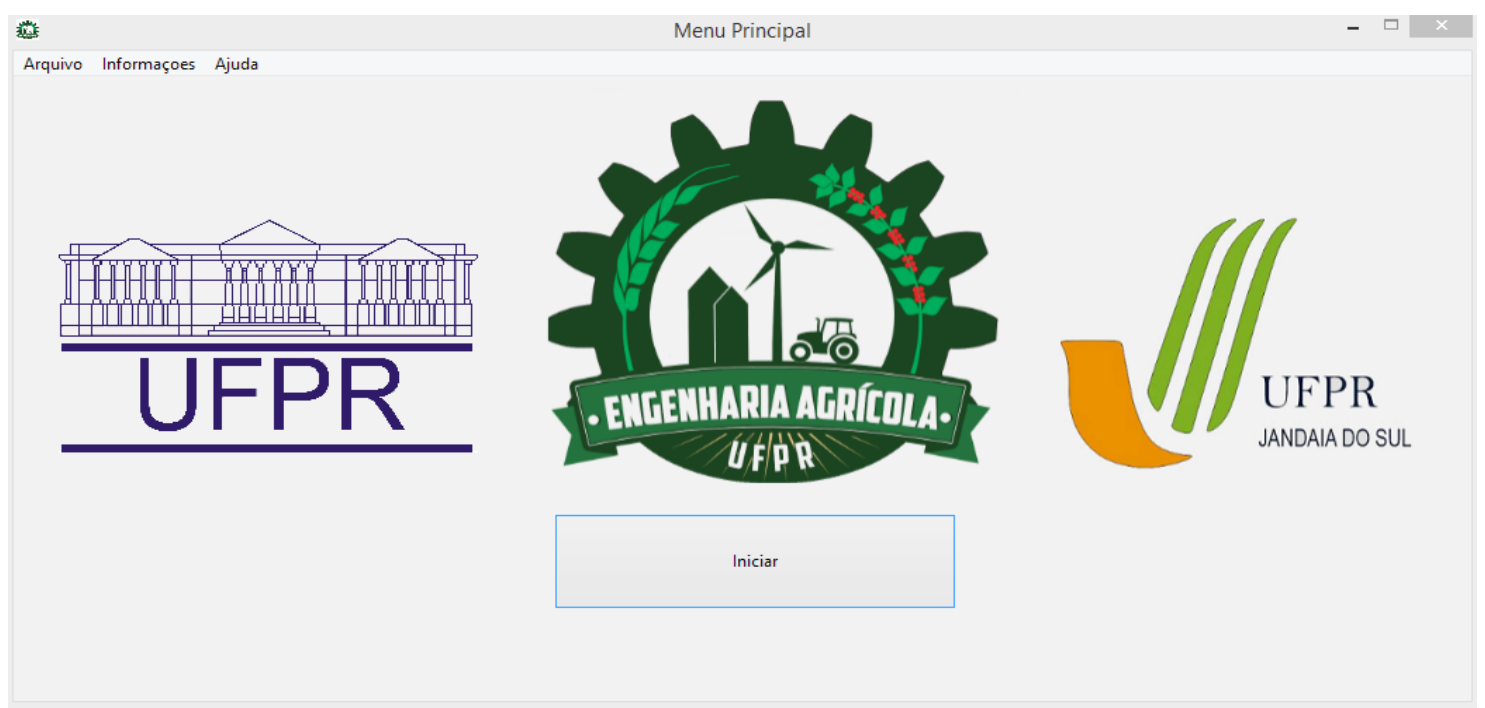

Figura 1. Configuração visual do menu principal do software.

O segundo formulário, assim como os demais, foi implementado para ser gerado em tempo real de execução, ou seja, para a máquina, eles não existem até serem requisitados, foi feito assim com o intuito de otimizar a execução do software via capacidade de processamento e memória do computador onde é executado. Nesse formulário foi adicionada uma caixa de texto indicando o líquido utilizado -no caso deste trabalho, água, ao lado da caixa de texto indicada como valor do diâmetro a ser inserido, fica outra caixa de opções, que dá acesso ao sistema de conversão de unidades, que faz a análise dimensional necessária. $\mathrm{O}$ valor da viscosidade cinemática é automaticamente preenchido. Sendo água, o valor da massa especifica é automaticamente preenchido de acordo com a temperatura, se estiver entre $0^{\circ} \mathrm{C}$ e $100^{\circ} \mathrm{C}$, com escala variando em 1 grau Célsius. Foram inseridas duas opções que verificam se a temperatura é ambiente ou não, se o resultado for positivo, o valor da temperatura é fixo em $20^{\circ} \mathrm{C}$, conforme literatura, e a viscosidade correspondente é preenchida automaticamente. Depois de inserida a vazão e o diâmetro, o programa verifica se não há dados em branco, em caso negativo, são calculados e apresentados os dados de velocidade e Número de Reynolds, utilizando as equações 1 e 2, respectivamente, além de apresentar a classificação do regime de escoamento.
$\mathrm{Q}=\mathrm{V} \cdot \mathrm{A}$

$\operatorname{Re}=\frac{\mathrm{V} \cdot \mathrm{D}}{\mathrm{v}}$

em que,

$\mathrm{Q}=$ vazão, em $\mathrm{m}^{3} \mathrm{~s}^{-1}$;

$\mathrm{V}=$ velocidade de escoamento, em $\mathrm{m} \mathrm{s}^{-1}$;

$\mathrm{A}=$ área de secção transversal do tubo, em $\mathrm{m}^{2}$;

$\mathrm{Re}=$ número de Reynolds, adimensional; $\mathrm{e}$

$\mathrm{v}=$ viscosidade cinemática, em $\mathrm{m}^{2} \mathrm{~s}^{-1}$.

Foram criados dois formulários idênticos, conforme mostra a Figura 2, para tubulação de sucção e tubulação de recalque.

Quando todos os espaços do formulário "regime de escoamento" forem preenchidos corretamente, é liberado o botão "avançar", dando acesso ao próximo formulário, que calcula as perdas de carga por três métodos diferentes, para as duas tubulações, na sequência, sucção e recalque. Ressalta-se que apenas algumas verificações são feitas antes de ser criado o próximo formulário e, tendo como referência PORTO (2006), foram adotadas as restrições para cálculo de perda de carga utilizando a equação de Hazen-Williams, ou seja, o diâmetro da tubulação ser maior ou igual a 4", o escoamento ser turbulento ou de transição e o líquido ser água a $20^{\circ} \mathrm{C}$, em que é considerado o efeito viscoso. No caso de alguma dessas verificações falhar, não é liberado o cálculo da perda de carga por esse método e, por último, é copiado o valor do diâmetro inserido anteriormente. 


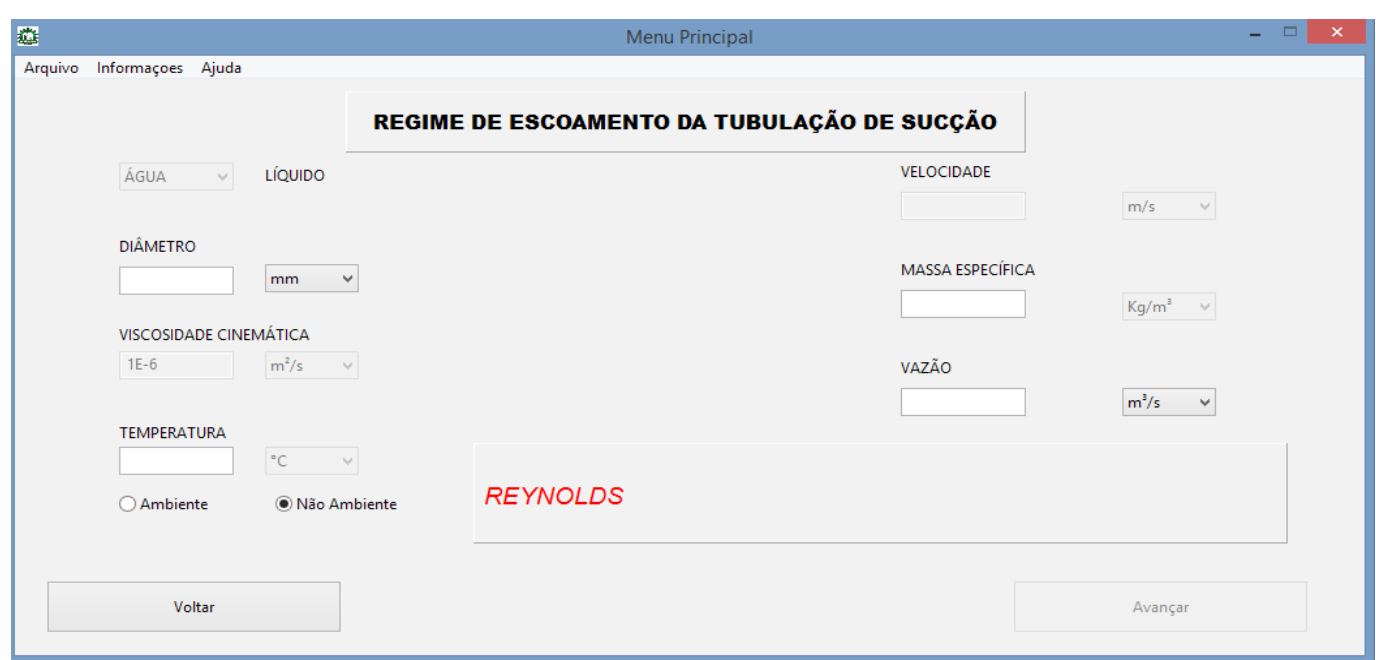

Figura 2. Configuração visual do formulário "regime de escoamento".

O terceiro formulário, apresentado na Figura 3 , fornece opções para escolha do material da tubulação e adição de seu comprimento. O preenchimento da rugosidade absoluta para a equação de Swamee-Jain, 1976 (Equação 3) é feito automaticamente, assim como o cálculo do fator de atrito, usado na equação universal da perda de carga, Equação de Darcy-Weisbach, (Equação 4). Outros métodos disponíveis para cálculo da perda de carga são: o coeficiente de rugosidade para a Equação de Hazen-Willians (Equação 5) e o coeficiente de atrito para a equação de Flamant (Equação 6).

$f=\left\{\left(\frac{64}{R e}\right)^{8}+9,5 \cdot\left[\ln \left(\frac{e}{3,7 . D}+\frac{5,74}{R^{0,9}}\right)-\left(\frac{2500}{R e}\right)^{6}\right]^{-16}\right\}^{0,125}$

$H f=\frac{f \cdot L \cdot v^{2}}{D \cdot 2 \cdot g}$

$H f=\frac{10,6451 \cdot Q^{1,852} \cdot L}{C^{1,852} \cdot D^{4,871}}$

$H f=\frac{6,107 \cdot L \cdot b \cdot Q^{1,75}}{D^{4,76}}$

em que,

$\mathrm{Hf}=$ perda de Carga, em m;

$\mathrm{f}=$ fator de atrito, adimensional;

$\mathrm{C}=$ coeficiente de rugosidade, $\mathrm{em} \mathrm{m}^{0,367}$;

$\mathrm{v}=$ velocidade, $\mathrm{em} \mathrm{m} / \mathrm{s}$;

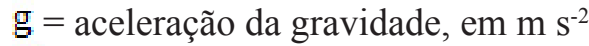

$\mathrm{Q}=$ vazão, $\mathrm{em} \mathrm{m} \mathrm{m}^{3} \cdot \mathrm{s}^{-1}$;
$\mathrm{D}$ = diâmetro, em m;

$\mathrm{L}=$ comprimento da tubulação, em $\mathrm{m}$;

$\mathrm{e}=$ coeficiente de rugosidade, $\mathrm{em} \mathrm{m}$;

$\mathrm{b}=$ coeficiente de atrito, adimensional; e

$\operatorname{Re}=$ número de Reynolds, adimensional;

Após o cálculo, o programa apresenta o valor da perda de carga para a tubulação de sucção e, posteriormente, recalque, permitindo a escolha de apenas uma das opções disponíveis a ser considerada nos cálculos subsequentes.

Para o cálculo da perda de carga localizada ocasionada pelas peças especiais, os formulários foram divididos em dois espaços principais, estando o primeiro à esquerda do visualizador (usuário), responsável por mostrar as perdas de carga na tubulação, previamente calculadas, e o segundo à direita do visualizador (usuário), onde estão os campos em que são calculadas as perdas para diferentes peças especiais, que devem ser escolhidas quanto ao tipo de peça no sistema e quantidade. Após a verificação e cálculo da perda de carga, o programa mostra o resultado e, automaticamente, abre mais espaços para inserção de novas peças, com um limite de até 15 peças diferentes, como indicado na Figura 4.

A metodologia utilizada para calcular a perda de carga em peças especiais é o método dos coeficientes (Equação 7), em que o coeficiente $\mathrm{K}$ (um número adimensional obtido experimentalmente para cada peça e situação), a velocidade do fluido, a quantidade de peças e a aceleração da gravidade são utilizados para os cálculos.

\section{REVENG}

ENGenharia NA Agricultura, ViçOSA - MG, V.24 N.6, NOVEMbro / DeZEMbro 2016 


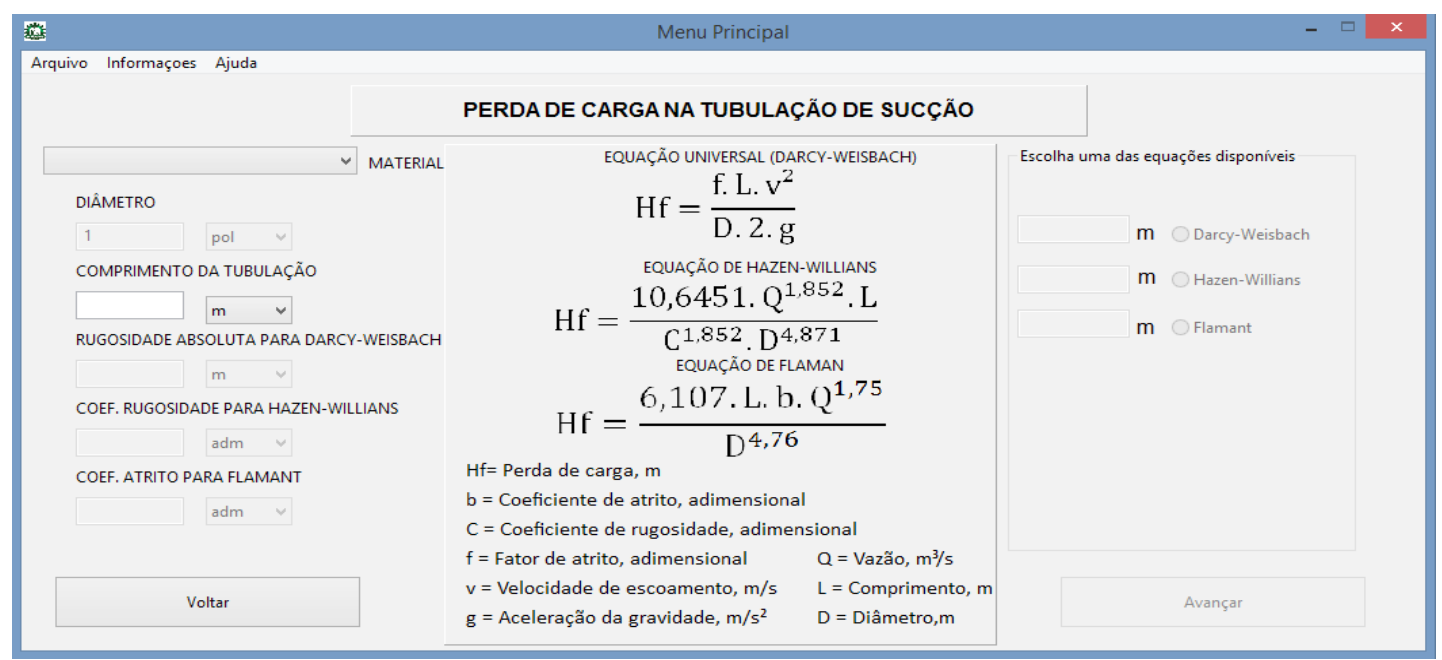

Figura 3. Configuração visual do formulário "perda de carga na tubulação"

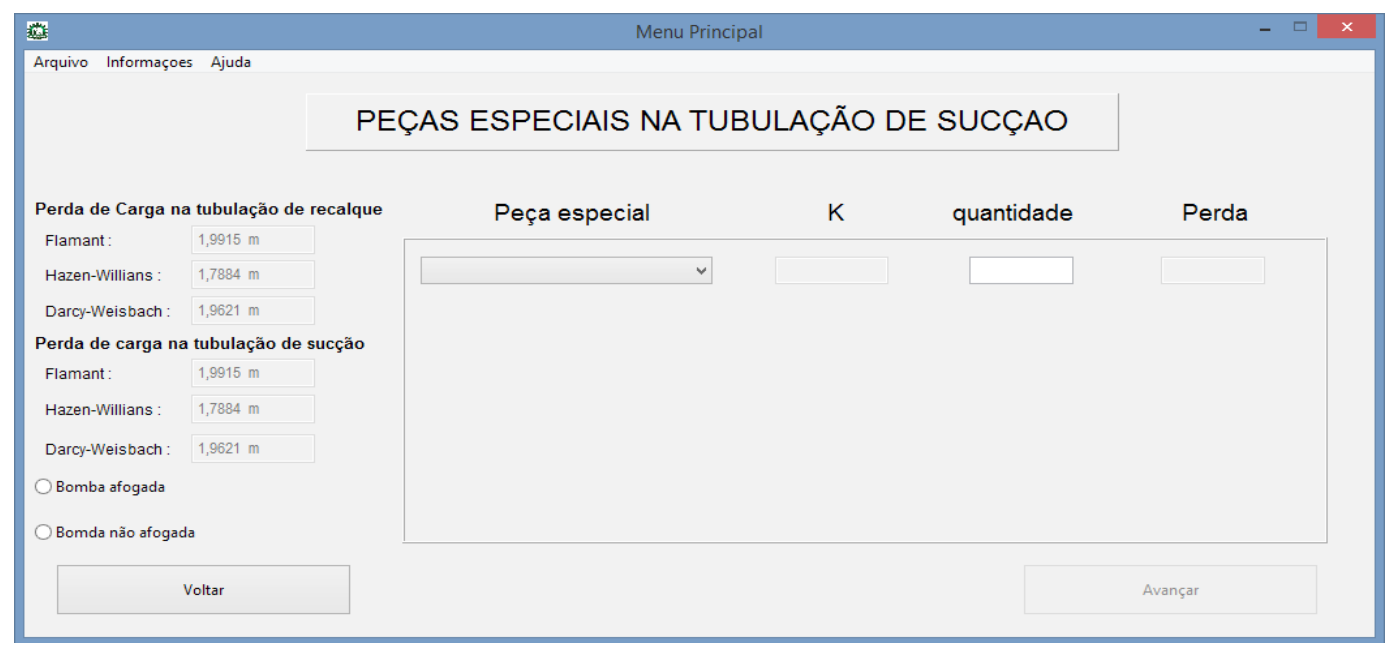

Figura 4. Formulário "Peças especiais".

$$
\mathrm{Hf}_{\mathrm{Loc}}=\frac{\mathrm{K} \cdot \mathrm{V}^{2} \cdot \mathrm{n}}{2 \cdot \mathrm{g}}
$$

em que,

$\mathrm{Hf}_{\text {Loc }}=$ perda de carga localizada, em m;

$\mathrm{K}=$ Valor obtido experimentalmente, adimensional;

$\mathrm{g}=$ Aceleração da gravidade, $\mathrm{em} \mathrm{m} / \mathrm{s}^{2} ; \mathrm{e}$

$\mathrm{n}=$ Número de peças especiais iguais;

O cálculo do N.P.S.H (Net Positive Suction Head) disponível, que é a energia do líquido imediatamente antes do flange de sucção da bomba, obtido pela equação 9 , é realizado após todos os elementos do formulário "elementos de perda e cavitação" (Figura 5) terem sido preenchidos, compreendendo as informações da altura geométrica de sucção (desnível entre a tubulação de sucção e a bomba), altura geométrica de recalque (desnível entre a tubulação de recalque e a bomba), perdas de carga nas tubulações de sucção e recalque (somatório das perdas de energia da água que ocorrem na tubulação de sucção e recalque, respectivamente) para altura manométrica total (Equação 8), pressão atmosférica local (estimada conforme o desnível em relação ao nível do mar), pressão de vapor d'água (estimada de acordo com a temperatura) e a soma de todas as perdas de carga na tubulação de sucção até a bomba. Há ainda a 
seleção de qual Equação será usada, resgatando informações do formulário anterior (peças especiais na tubulação de recalque), caso a bomba esteja submersa (bomba afogada), Equação 9, caso não esteja (bomba não afogada):

\section{$\mathrm{Hmt}=\mathrm{Hgs}+\mathrm{Hgr}+\mathrm{Hfs}+\mathrm{Hf} r$}

N.P.S. $H_{D}=\frac{{ }^{P} \cdot P_{v}}{Y} \pm Z-\left(H_{S 1}\right)$

em que,

$\mathrm{Hmt}=$ Altura manométrica total, em m;

Hgs = Altura geométrica da tubulação de sucção, em m; $\mathrm{Hgr}=$ Altura geométrica da tubulação de recalque, em m; $\mathrm{Hfs}=$ Perda de carga na tubulação de sucção, em m;

$\mathrm{Hfr}=$ Perda de carga na tubulação de recalque, em m; $\mathrm{Hfr}=$ Perda de carga na tubulação de recalque, em m; N.P.S. $\mathrm{H}_{\mathrm{D}}=$ Energia disponível, em m;

$\mathrm{Pa}=$ Pressão atmosférica por área da tubulação, em Kgf.m²;

$\mathrm{Pv}=$ Pressão do vapor d'água por área da tubulação, em Kgf.m²;

$\mathrm{Y}=$ Peso específico do líquido, em Kgf.m;

$\mathrm{Z}=$ Altura estática de sucção, em m; e

$\mathrm{H}_{\mathrm{S} 1}=$ Somatório de todas as perdas de carga até a entrada da bomba, em $\mathrm{m}$.

Em relação ao N.P.S.H disponível, existem recomendações na literatura da inclusão no cálculo de um coeficiente de segurança. Porém, para tal, existe variação de recomendação, sendo esse item, portanto, suprimido do software, mas não deixando de ser indicada essa recomendação. Fica, então, a cargo do usuário/projetista determinar qual coeficiente de segurança a ser utilizado.

Foi reservado um espaço do formulário dedicado a mostrar os resultados obtidos, configurando um resumo do sistema, onde podem ser visualizadas informações sobre a tubulação de sucção, tubulação de recalque, ou nenhuma das duas. Quando não houver espaço em branco, o software exibe os resultados nos campos indicados.

$\mathrm{Na}$ sequência de páginas do programa, a próxima é responsável, no primeiro momento, pelo cálculo da potência hidráulica ou útil (potência que realmente é transmitida ao líquido, Equação 10) e logo após, da potência absorvida no eixo da bomba (potência hidráulica, acrescida das perdas mecânicas da bomba, Equação 11). Para que seja possível a realização desses cálculos, o software resgata informações disponíveis na memória, acessíveis em formato de variáveis e traduz em formato de texto tanto a vazão, quanto a altura total de elevação, assim como requisita a inserção da potência escolhida (em \%) e converte todas as unidades dos dados necessários para garantir que o resultado final da potência absorvida no eixo da bomba seja exibido em cavalos.

$\mathrm{P}_{\mathrm{h}}=\frac{\mathrm{Q} \cdot \mathrm{H} \cdot 1000}{75}$

$\mathrm{P}_{\mathrm{b}}=\frac{\mathrm{P}_{\mathrm{h}}}{\mathrm{N}_{\mathrm{b}}}$

em que,

$\mathrm{P}_{\mathrm{h}}=$ Potência hidráulica ou útil, em CV;

$\mathrm{P}_{\mathrm{b}}=$ Potência absorvida no eixo da bomba, em CV;

$\mathrm{Q}=$ Vazão, em $\mathrm{m}^{3} \mathrm{~s}^{-1}$;

$\mathrm{H}=$ Altura manométrica, em $\mathrm{m}$; e

$\mathrm{N}_{\mathrm{h}}=$ Rendimento da bomba, adimensional.

Ainda no formulário "potência da bomba", existem duas possibilidades para dar seguimento aos cálculos, que dependem do tipo de motor, sendo possível escolher entre motor elétrico ou a combustão, como mostra a Figura 6 .

Para ROMANI, MAGALHÃES e EVANGELISTA (2015), a inclusão de mais de uma seção de "ajuda" e "informações adicionais ao projeto", tornam a consulta mais simples, mantendo, assim, o status didático do software. No formulário do motor a combustão (Figura 7), existem opções de combustíveis que podem ser utilizados no cálculo da estimativa do custo anual de bombeamento. Foi feita, ainda dentro dessa página, uma janela que tem como finalidade auxiliar em caso de dúvidas sobre o método de cálculo utilizado, basta clicar no botão "AJUDA" e são mostradas, em tempo de execução, as fórmulas utilizadas e o significado de cada componente constituinte (Figura 8). 


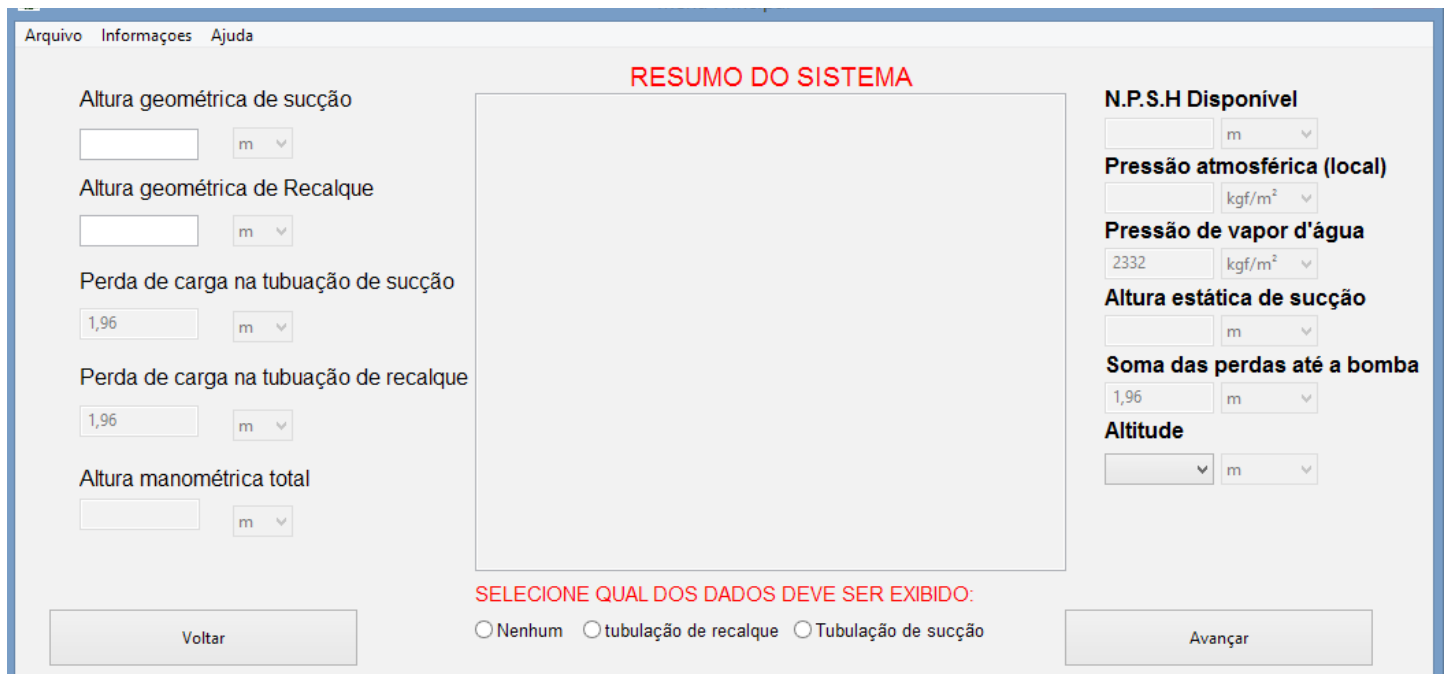

Figura 5. Formulário "elementos de perda e cavitação".

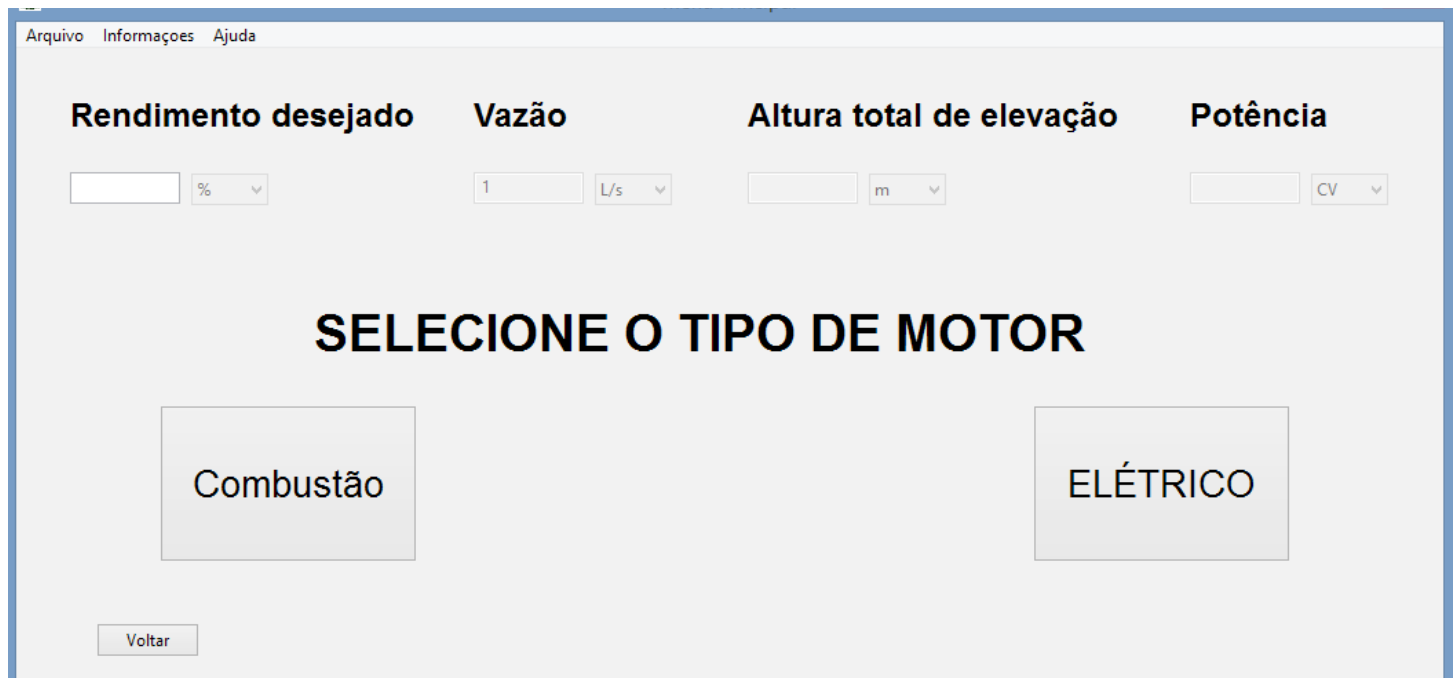

Figura 6. Formulário potência da bomba.

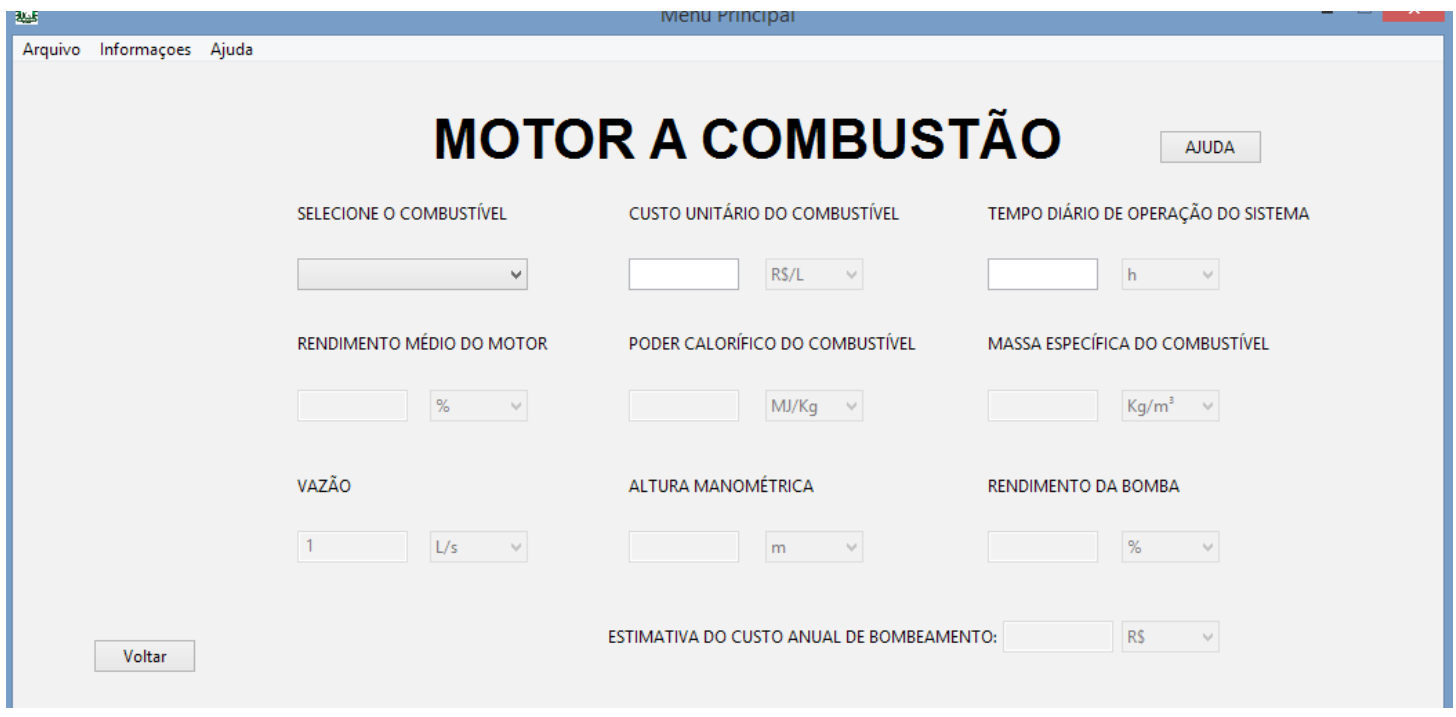

Figura 7. Formulário "Motor a combustão 


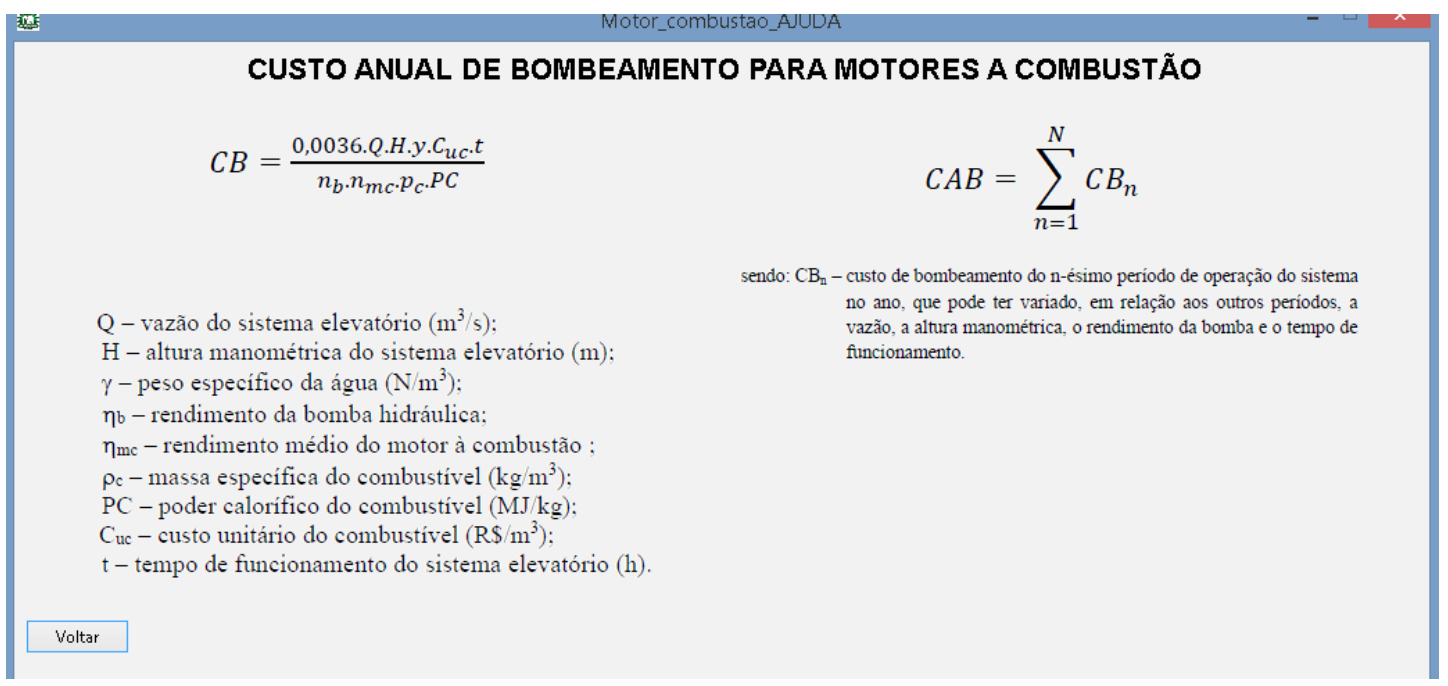

Figura 8. Página de ajuda do formulário "Motor a combustão"

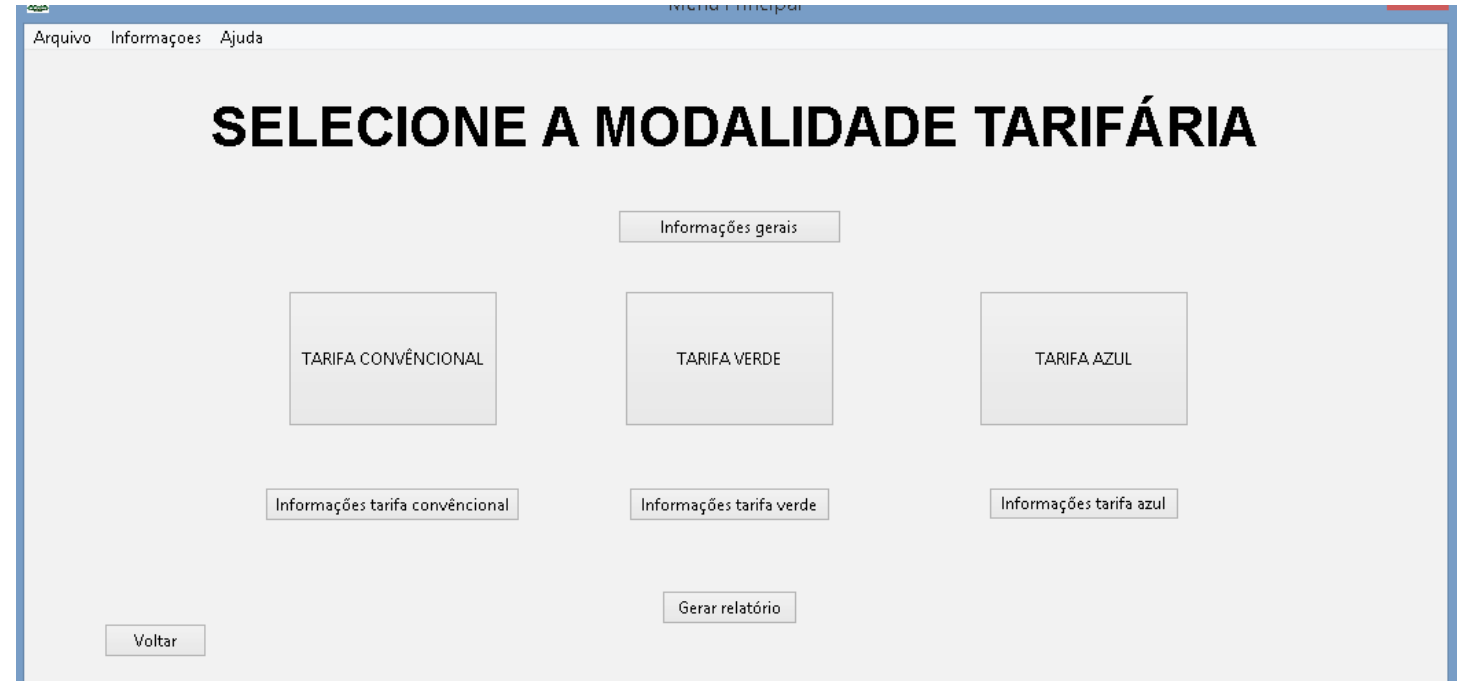

Figura 9. Formulário "Modalidade tarifária".

Existe também, no formulário "potência da bomba", a opção de selecionar o motor elétrico, clicando no botão "elétrico" (Figura 6), nessa parte do software existem 3 opções para cálculo do custo anual de bombeamento $(\mathrm{CAB})$, descrito nesse mesmo formulário em "informações gerais", corroborando com MERCANTE et. al. (2010), que chama atenção para a importância da contabilização de custos no planejamento agrícola, assim como sua persistência em meio físico; sendo esse último contemplado na parte central inferior, na qual foi disponibilizado um gerador automático de relatórios, apresentado na Figura 14. Esses relatórios podem ser salvos em formato PDF(Portable Document Format), o que possibilita e facilita sua posterior impressão.

$\mathrm{O}$ cálculo do custo anual de bombeamento feito pelo software foi dividido em 3 etapas, nas modalidades tarifárias convencional, verde e azul. A subdivisão da equação responsável pelo $\mathrm{CAB}$ obtido se fez necessária devido à complexidade dos processos matemáticos envolvidos, e são feitas de acordo com a Equação 12, na qual ele é a soma do FAD (Faturamento anual de demanda), FAC (Faturamento Anual de Consumo) e AJA (Ajuste Anual, referente ao fator de deslocamento do sistema elétrico, $\cos (\theta)$ ), processados separadamente e depois unidos pelo programa. Essa equação é adaptada do Comitê de Distribuição de Energia Elétrica - CODI (1988) apud MARQUES 
(2005), e foi descrita de forma visual no software dentro da página "modalidade tarifaria", no botão central superior "Informações gerais", apresentada nas Figuras 9 e 10.

\section{$\mathrm{CAB}=\mathrm{FAD}+\mathrm{FAC}+\mathrm{AJA}$}

em que,

$\mathrm{CAB}=$ Custo Anual de bombeamento, em R $\$$

$\mathrm{FAD}=$ Faturamento Anual de Demanda, em R\$;

$\mathrm{FAC}=$ Faturamento Anual de Consumo, em R\$; e $\mathrm{AJA}=$ Ajuste Anual, em R\$;

O software possui um layout simples, com agrupamentos de termos semelhantes, verificações para correções de erros de inserção de dados, além de dicas ao longo de toda sua extensão e áreas de ajuda (Figura 11), que têm o objetivo de auxiliar na utilização das ferramentas disponíveis, compreendendo as fórmulas que estão por trás da interface do programa. Sendo assim, as três páginas que contemplam o $\mathrm{CAB}$ das modalidades tarifárias convencional, azul e verde não poderiam ser diferentes, ou seja, apresentam todas essas características, seguindo o mesmo padrão do formulário para estimativa da modalidade tarifária convencional (Figura 12).

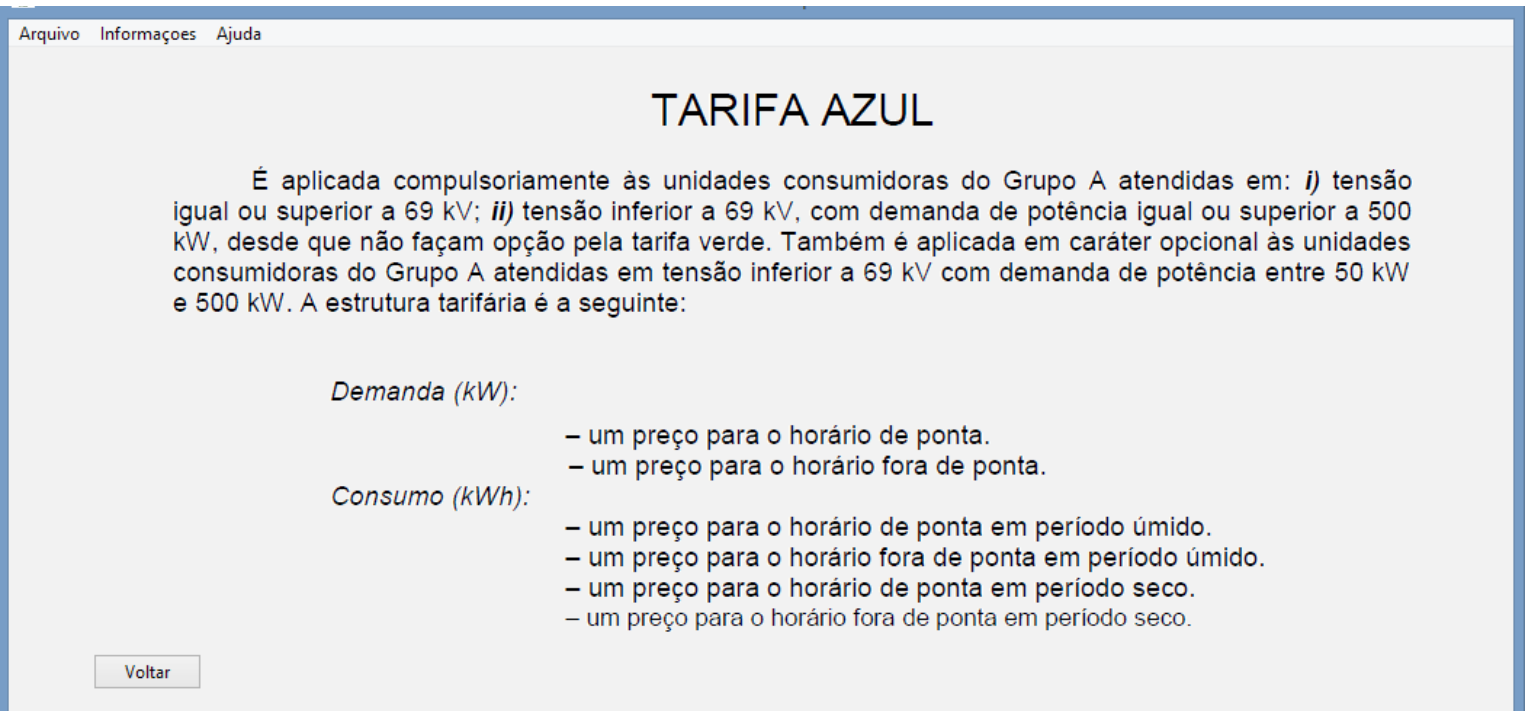

Figura 10: Formulário "Informações gerais, tarifa azul".

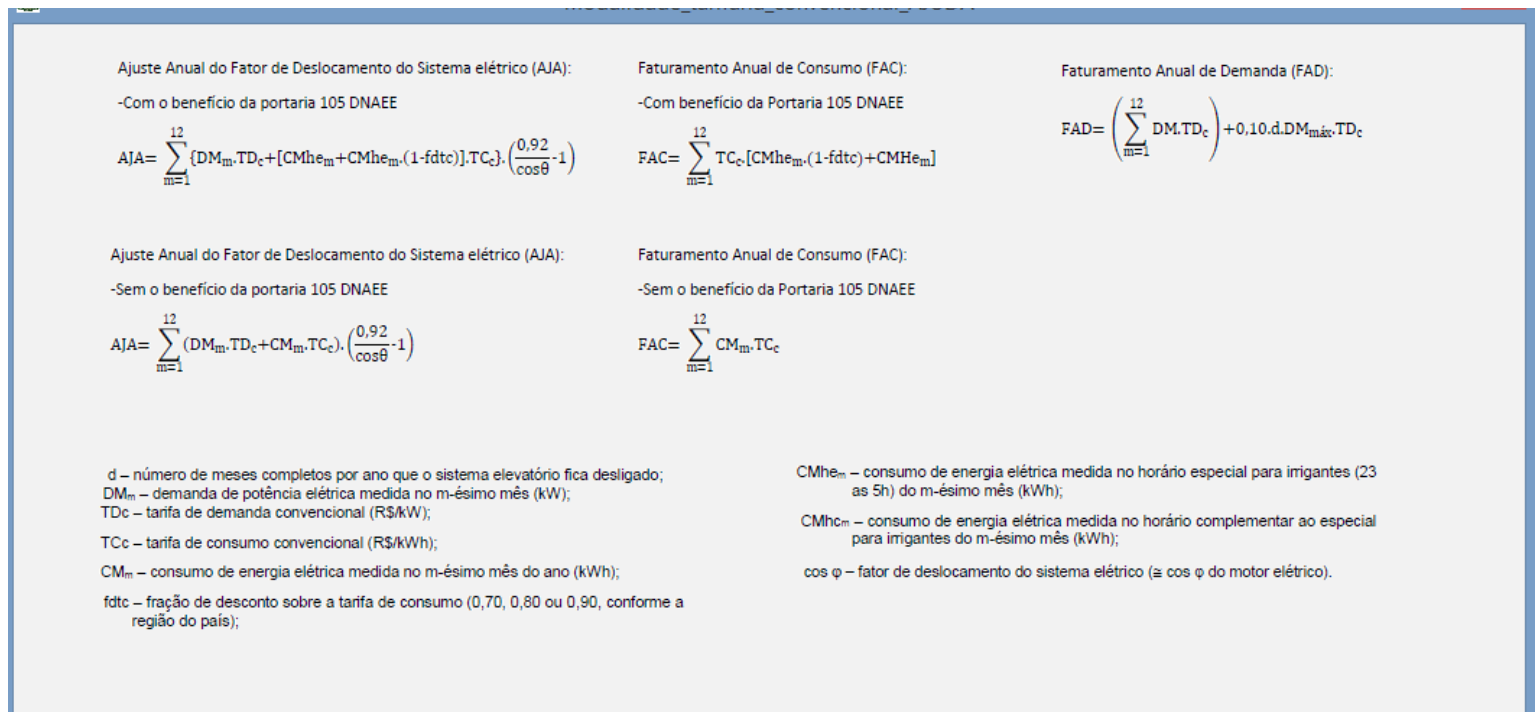

Figura 11: Formulário "Ajuda da modalidade tarifaria convencional". 


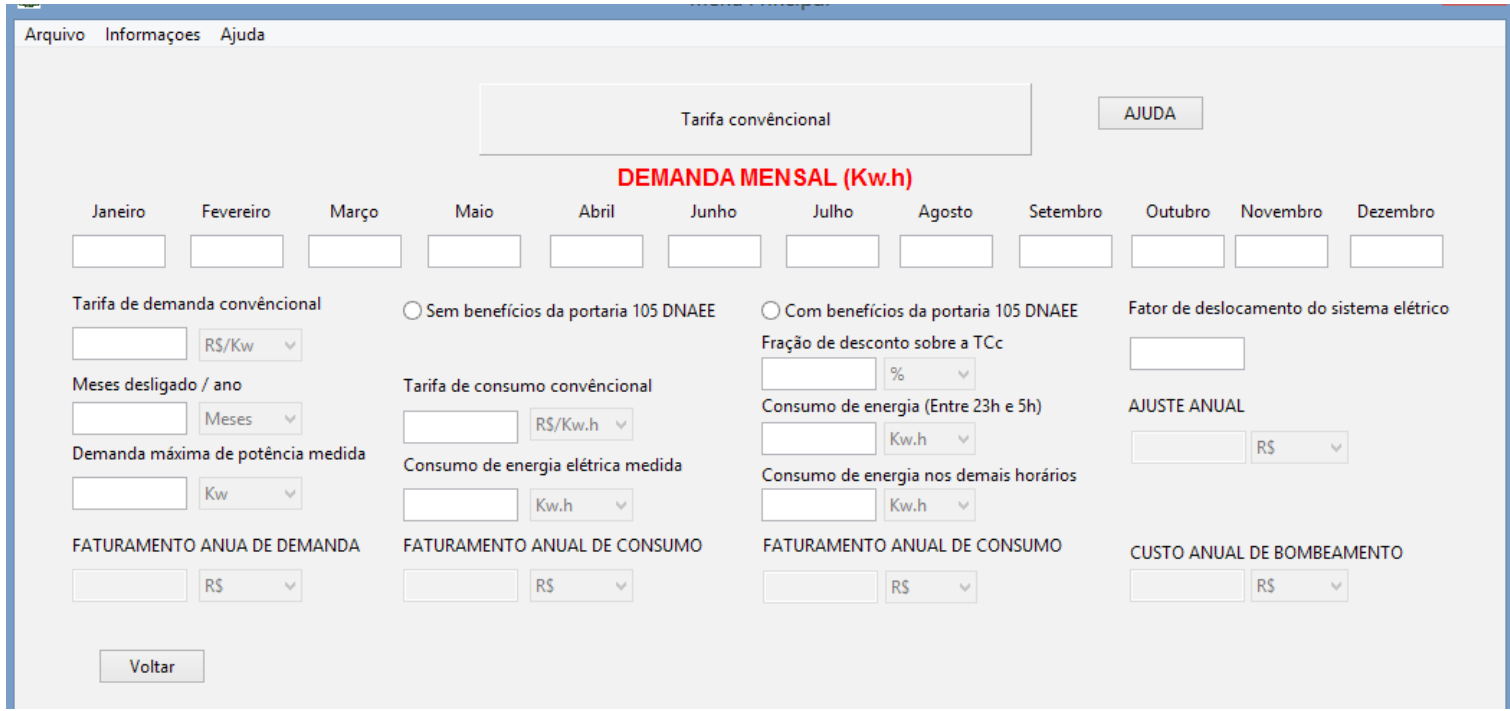

Figura 12. Formulário "Modalidade tarifária convencional".

As equações utilizadas nos cálculos da tarifa convencional são: FAD (Equação 13), FAC sem benefício da portaria 105 DNAEE (Departamento Nacional de Águas e Energia Elétrica), (Equação 14), com benefício da portaria 105 DNAEE (Equação 15), AJA sem benefício da portaria 105 DNAEE (Equação 16) e AJA com benefício da portaria 105 DNAEE (Equação 17). Para a tarifa verde foram utilizadas as equações: FAD (Equação 18), FAC sem benefício da portaria 105 DNAEE (Equação 19), FAC com benefício da portaria 105 DNAEE (Equação 20), AJA sem benefício da portaria 105 DNAEE (Equação 21) e AJA com benefício da portaria 105 DNAEE (Equação 22). Por fim, para a tarifa azul foram utilizadas: FAD (Equação 23), FAC sem benefício da portaria 105 DNAEE (Equação 24), FAC com benefício da portaria 105 DNAEE (Equação 25), AJA sem benefício da portaria 105 DNAEE (Equação 26) e AJA com benefício da portaria 105 DNAEE (Equação 27).

Os cálculos que culminam na estimativa do custo anual de bombeamento para sistemas elétricos requerem cuidados especiais, que serão descritos a seguir, assim como suas respectivas fórmulas utilizadas pelo software.

Começando pelo Faturamento Anual de Demanda da tarifa convencional (equação 13), deve-se atentar para o fato de que o faturamento de demanda correspondente a $10 \%$ da maior demanda medida nos últimos 11 meses, portanto, o número de meses completos por ano que o sistema elevatório fica desligado deve ser menor ou igual a 11 meses; já no faturamento anual de consumo (Equação 15), com o benefício da portaria 105 (portaria responsável por estimular a otimização do uso da energia no meio agrícola e conceder descontos quando cumpridas determinadas restrições) do DNAEE deve-se atentar para o fdtc (fração de desconto sobre a tarifa de consumo), que pode variar de acordo com a região do país e o horário especial para irrigantes, que no Brasil vai de $23 \mathrm{~h}$ até as $5 \mathrm{~h}$, além do mais, no AJA, o cos $\theta$ (Fatora de Deslocamento do Sistema Elétrico) deve ser menor ou igual a $92 \%$, caso contrário, a equação 17 não poderá ser aplicada

$$
\begin{aligned}
& F A D=\left[\left(\sum_{m=1}^{12} D_{m} \cdot T D_{c}\right)+0,10 \cdot d \cdot D M_{m a ́ x} \cdot T D_{c}\right] \\
& F A C=\left[\sum_{m=1}^{12} C_{m} \cdot T C_{c}\right] \\
& F A C=\left[\sum_{m=1}^{12} T_{c}\left[C M h e_{m} \cdot(1-f d t c)+C M h c_{m}\right]\right] \\
& A J A=\left[\sum_{m=1}^{12}\left(D_{m} \cdot T_{c}+C M_{m} \cdot T C c\right) \cdot\left(\frac{0,92}{\cos \theta}-1\right)\right] \\
& A J A=\left[\sum_{m=1}^{12}\left\{D_{m} \cdot T D_{c}+\left[\mathrm{CMhc}_{m}+C M_{m} \cdot(1-f d c)\right] \cdot T C c\right\} \cdot\left(\frac{0,92}{\cos \theta}-1\right)\right]
\end{aligned}
$$

em que,

$\mathrm{DM}_{\mathrm{m}}=$ Demanda de potência elétrica medida no m-ésimo mês, em kW;

$\mathrm{DM}_{\text {máx }}=$ Demanda máxima de potência medida no m-ésimo mês, em kW;

$\mathrm{CM}_{\mathrm{m}}=$ Consumo de energia elétrica medida no m-ésimo mês do ano, em kWh;

$\mathrm{TD}_{\mathrm{c}}=$ Tarifa de demanda convencional, em 
$\mathrm{R} \$ .(\mathrm{kW})^{-1}$;

$\mathrm{TC}_{\mathrm{c}}=$ Tarifa de consumo convencional, em $\mathrm{R} \$ .(\mathrm{kWh})^{-1}$;

$\mathrm{CMhe}_{\mathrm{m}}=$ Consumo de energia elétrica medida no horário especial para irrigantes $(23$ as $5 \mathrm{~h})$ do m-ésimo mês, em kWh;

$\mathrm{CMhc}_{\mathrm{m}}=$ Consumo de energia elétrica medida no horário complementar ao especial para irrigantes do m-ésimo mês, em kWh;

$\mathrm{d}=$ Número de meses completes por ano que o Sistema elevatório fica desligado;

fdtc $=$ Fração de desconto sobre a tarifa de consumo, adimensional; e

$\operatorname{Cos}^{\theta}=$ Fator de deslocamento do Sistema elétrico.

$\mathrm{Na}$ tarifa verde, os cuidados devem ser voltados para a TUv (Tarifa de Ultrapassagem de Demanda verde) nas equações 18,21 e 22 , que somente é aplicada se a demanda medida for superior a $10 \%$ da demanda contratada, quando a demanda contratada for superior a $100 \mathrm{KW}$ ou se a demanda medida for superior a $20 \%$ da demanda contratada, quando a demanda contratada for de $50 \mathrm{KW}$ a $100 \mathrm{KW}$.

$$
\begin{aligned}
& F A D=\left[\left[\sum_{m=1}^{12} D_{m}+T_{v}+\left(D M_{m}-D C\right) \cdot T U v\right]+0,10 \cdot d \cdot D M_{\text {máx }} \cdot T_{v}\right] \\
& F A C=\left[\begin{array}{c}
\sum_{m u=1}^{5} \mathrm{CM}_{\mathrm{pmu}} \cdot \mathrm{TC}_{\mathrm{vup}}+\mathrm{CMfp}_{\mathrm{mu}} \cdot \mathrm{TCvufp}+ \\
\sum_{\mathrm{ms}=1}^{7} \mathrm{CMp}_{\mathrm{ms}} \cdot \mathrm{TCvsp}+\mathrm{CMfp}_{\mathrm{ms}} \cdot \mathrm{TCvsfp}
\end{array}\right] \\
& F A C=\left[\begin{array}{c}
\sum_{m u=1}^{7} \mathrm{CMp}_{\mathrm{ms}} \cdot \mathrm{TCvsp}^{\prime}\left[\mathrm{CMfpc}_{\mathrm{mu}}+\mathrm{CMhe}_{\mathrm{mu}} \cdot(1-\mathrm{fdtc})\right] \cdot \mathrm{TCvufp}+ \\
\sum_{\mathrm{ms}=1}^{7} \mathrm{CMp}_{\mathrm{ms}} \cdot \mathrm{TCvsp}^{\prime}+\left[\mathrm{CMfpc}_{\mathrm{ms}}+\mathrm{CMhe}_{\mathrm{ms}} \cdot(1-\mathrm{fdtc})\right] \cdot \mathrm{TCvsfp}
\end{array}\right]
\end{aligned}
$$

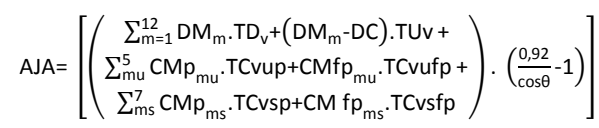

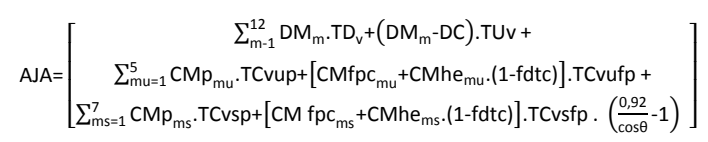

em que,

$\mathrm{DC}=$ Demanda contratada com a concessionária de energia elétrica, em $\mathrm{kW}$;

$\mathrm{CMp}_{\mathrm{mu}}=$ Consumo medido no horário de ponta (17 as $21 \mathrm{~h}$ ou definida pela Concessionária) do muésimo mês do período úmido, em $\mathrm{kWh}$;

CMufp $=$ Consumo medido no horário fora de ponta do mu-ésimo mês do período úmido, em KWh;

$\mathrm{CMp}=$ Consumo medido no horário de ponta do ms-ésimo mês do período seco, em kWh;

CMsfp = Consumo medido no horário fora de ponta do ms-ésimo mês do período seco, em $\mathrm{kWh}$;
$\mathrm{CMhe}_{\mathrm{mu}}=$ consumo medido no horário especial para irrigantes do um

ésimo mês do período úmido, em $\mathrm{kWh}$;

$\mathrm{CMfpc}_{\mathrm{mu}}=$ consumo medido no horário fora de ponta complementar ao horário especial para irrigantes do mu-ésimo mês do período úmido, em kWh;

$\mathrm{CMhe}_{\mathrm{ms}}=$ consumo medido no horário especial para irrigantes do ms-ésimo mês do período seco, em kWh;

$\mathrm{CMfpc}_{\mathrm{ms}}=$ consumo medido no horário fora de ponta complementar ao horário especial para irrigantes do ms-ésimo mês do período seco, em $\mathrm{kWh}$;

$\mathrm{TDv}=$ Tarifa de demanda verde, em R $\$ .(\mathrm{kW})^{-1}$;

$\mathrm{TUv}=$ Tarifa de ultrapassagem de demanda verde $\mathrm{R} \$(\mathrm{~kW})^{-1}$;

TCvup $=$ Tarifa de consumo verde no período úmido, no horário de ponta, em R $\$(\mathrm{kWh})^{-1}$;

TCvufp $=$ Tarifa de consumo verde no período úmido, no horário fora de ponta, em $\mathrm{R} \$ .(\mathrm{kWh})^{-1}$;

TCvsp $=$ Tarifa de consumo verde no período seco no horário de ponta, em R $\$$. $(\mathrm{kWh})^{-1}$; e

TCvsfp $=$ Tarifa de consumo verde no período seco no horário fora de ponta, em $\mathrm{R} \$ .(\mathrm{kWh})^{-1}$.

$\mathrm{Na}$ tarifa azul existem restrições para utilização das equações, no FAD (Equação 23) devem ser observadas as condições: A demanda contratada no período úmido no horário fora de ponta não deve ser inferior a demanda contratada no período úmido, no horário de ponta; A demanda contratada no período seco, no horário fora de ponta, não poderá ser inferior a demanda contratada no período seco, no horário de ponta, e também não poderá ser superior a demanda contratada no período úmido, no horário fora de ponta; $\mathrm{O}$ número de meses completos que o sistema elevatório fica desligado, no período úmido do ano, no horário de ponta e no horário fora de ponta, é limitado a no máximo 5 meses cada, já o número de meses completos que o sistema elevatório fica desligado no período seco do ano, no horário de ponta e fora de ponta, deve ser igual ou inferior a 7 meses cada; A tarifa de ultrapassagem de demanda azul, tanto no horário de ponta, quanto no horário fora de ponta, será aplicada somente se a demanda medida em um ou em ambos os casos for superior a $10 \%$ da demanda contratada para o segmento fora de ponta, quando a demanda contratada no respectivo segmento for superior a $100 \mathrm{Kw}$, a demanda medida em um ou ambos os casos for superior a $20 \%$ da demanda 
contratada para o segmento fora de ponta, quando a demanda contratada no respectivo segmento for de $50 \mathrm{Kw}$ a $100 \mathrm{Kw}$. Os termos (DMfp ${ }_{\text {mu }}$-DCup). TUap, (DMfp ${ }_{\mathrm{mu}}$-DCufp).TUafp, (DMp $\left.\mathrm{ms}_{\mathrm{ms}}-\mathrm{DCsp}\right)$. TUap e (DMfp ${ }_{\mathrm{ms}}$-DCsfp).TUafp, não são aplicados se isso não ocorrer.

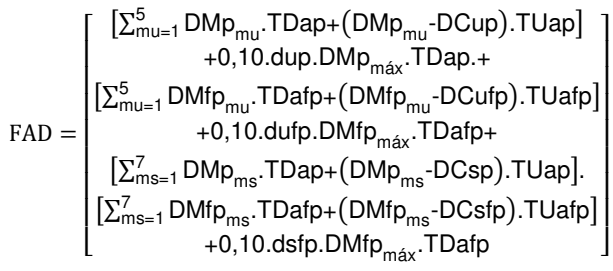

$\mathrm{FAC}=\left[\begin{array}{c}\sum_{\mathrm{mu}=1}^{5} \mathrm{CMp}_{\mathrm{mu}} \cdot \mathrm{TCaup}_{+} \mathrm{CMfp}_{\mathrm{mu}} \cdot \mathrm{TCaufp}_{+} \\ \sum_{\mathrm{ms}=1}^{7} \mathrm{CMp}_{\mathrm{ms}} \cdot \mathrm{TCasp}_{+}+\mathrm{CMfp}_{\mathrm{ms}} \cdot \mathrm{TCasp}_{+} \mathrm{CMfp}_{\mathrm{ms}} \cdot \mathrm{TCasfp}\end{array}\right]$

$\mathrm{FAC}=\left[\begin{array}{c}\sum_{\mathrm{mu}=1}^{5} \mathrm{CMp}_{\mathrm{mu}} \cdot \mathrm{TCaup}+\left[\begin{array}{c}\mathrm{CMfpc}_{\mathrm{mu}}+ \\ \mathrm{CMhe}_{\mathrm{mu}} \cdot(1-\mathrm{fdtc})\end{array}\right] \cdot \mathrm{TCaufp}+\mathrm{CMp}_{\mathrm{ms}} \cdot \mathrm{TCasp}+ \\ \sum_{\mathrm{ms}=1}^{7}\left[\mathrm{CMfpc}_{\mathrm{ms}}+\mathrm{CMhe}_{\mathrm{ms}} \cdot(1-\mathrm{fdtc})\right] \cdot \mathrm{TCasfp}\end{array}\right]$

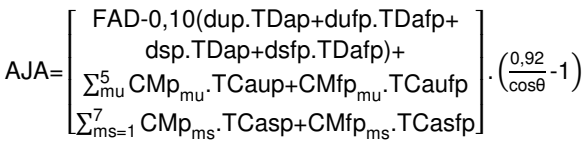

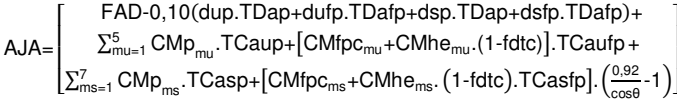

em que,

$\mathrm{DMp}_{\mathrm{mu}}=$ Demanda de potência medida no horário de ponta do mu-ésimo mês do período úmido do ano, em kW;

$\mathrm{DMfp}_{\mathrm{mu}}=$ Demanda de potência medida no horário fora de ponta do mu-ésimo mês do período úmido do ano, em kW;

$\mathrm{DMp}_{\mathrm{ms}}=$ Demanda de potência medida no horário de ponta do mu-ésimo mês do período seco do ano, em kW;

$\mathrm{DMfp}_{\mathrm{ms}}=$ Demanda de potência medida no horário fora de ponta do mu-ésimo mês do período seco do ano, em kW;

DCup $=$ Demanda contratada no período úmido, no horário de ponta, em $\mathrm{kW}$;

DCufp = Demanda contratada no período úmido, no horário fora de ponta, em $\mathrm{kW}$;

DCsp = Demanda contratada no período seco, no horário de ponta, em $\mathrm{kW}$;

DCsfp = Demanda contratada no período seco, no horário fora de ponta, em $\mathrm{kW}$.

TDap = Tarifa de demanda azul no horário de ponta, em R $\$ .(\mathrm{kW})^{-1}$;

TDafp $=$ Tarifa de demanda azul no horário fora de ponta, em R\$.(kW)-';
TUap $=$ Tarifa de ultrapassagem de demanda azul no horário de ponta, em R\$.(kW) ${ }^{-}$;

TUafp = Tarifa de ultrapassagem de demanda azul no horário fora de ponta, em R\$.(kW-“;

TCaup $=$ Tarifa de consumo azul no período úmido, no horário de ponta, em $\mathrm{R} \$,(\mathrm{kWh})^{-1}$;

TCaufp = Tarifa de consumo azul no período úmido, no horário fora de ponta, em $\mathrm{R} \$ .(\mathrm{kWh})^{-1}$;

TCasp $=$ Tarifa de consumo azul no período seco, no horário de ponta, em R $\$ .(\mathrm{kWh})^{-1}$;

TCasfp $=$ Tarifa de consumo azul no período seco, no horário fora de ponta, em $\mathrm{R} \$ .(\mathrm{kWh})^{-1}$.

dup $=$ Número de meses completos que o sistema elevatório fica desligado no período úmido do ano no horário de ponta;

dufp = Número de meses completos que o sistema elevatório fica desligado no período úmido do ano no horário fora de ponta;

dsp = Número de meses completos que o sistema elevatório fica desligado no período seco do ano no horário de ponta; e

dsfp = Número de meses completos que o sistema elevatório fica desligado no período seco do ano no horário fora de ponta.

Um procedimento adotado em todas as etapas de desenvolvimento do software, a concatenação (união de dados iguais ou diferentes), sempre um valor real, com um ou mais textos, permitiu que fossem gerados resultados com layout simples e objetivo, sem poluir as páginas com elementos desnecessários. Isso ficou evidente quando o relatório gerado estava em fase de testes, e pode ser observado nas colunas "Resultados" da Figura 14.

Outro procedimento importante adotado durante o desenvolvimento foi a geração dos formulários em tempo de execução, quando necessário. Esse tipo de comportamento ajuda a não ocupar espaço em memória sem necessidade, uma vez que, ao abrir o programa, alguns formulários ainda não existem, até que sejam criados, quando requisitados.

Para HONDA e JORGE (2013), a utilização de técnicas computacionais permite o desenvolvimento de um conjunto de soluções para suprir necessidades de informação para o agricultor. Nesse viés, o presente software se justifica e se caracteriza como uma ferramenta de extrema importância, pois permite ao agricultor e ao profissional da área, a execução simples e precisa dos cálculos necessários para o dimensionamento de sistemas hidráulicos, podendo ainda apresentar a estimativa dos custos de bombeamento.

\footnotetext{
502 REVENG 491-504p 


\section{DIMENSIONAMENTO DO SISTEMA DE RECALQUE HIDRAULICO}

\section{DADOS DA TUBULAÇAO DE SUCÇAOO DO SISTEMA}

\begin{tabular}{l|c|l}
\hline \multicolumn{1}{c|}{ Dados obtidos } & Resultados & Informações importantes \\
\hline Vazão: & $4 \mathrm{~L} / \mathrm{s}$ & \\
Velocidade & $0,49 \mathrm{~m} / \mathrm{s}$ & \\
Número de Reynolds: & $50.127,54$ & \\
Perda de carga (Darcy-Wesback): & $1,1409 \mathrm{~m}$ & Indicado pelo usuário para ser usado nos cálculos subsequentes \\
Perda de carga (Hazen-Willians): & $1,0986 \mathrm{~m}$ & \\
Perda de carga (Flaman): & $1,2277 \mathrm{~m}$ & \\
Perdas de carga em peças especiais: & $0,13 \mathrm{~m}$ & \\
\end{tabular}

DADOS DA TUBULAÇAO DE RECALQUE DO SISTEMA

\begin{tabular}{l|c|c}
\multicolumn{1}{c|}{ Dados obtidos } & Resultados & Informações importantes \\
\hline Vazäo: & $4 \mathrm{~L} / \mathrm{s}$ & \\
Velocidade: & $0,49 \mathrm{~m} / \mathrm{s}$ & \\
Número de Reynolds: & $50.127,54$ & \\
Perda de carga (Darcy-Wesback): & $1,1409 \mathrm{~m}$ & \\
Perda de carga (Hazen-Willians): & $1,0986 \mathrm{~m}$ & Indicado pelo usuário para ser usado nos cálculos subsequentes \\
Perda de carga (Flaman): & $1,2277 \mathrm{~m}$ & \\
Perdas de carga em peças especiais: & $0,1 \mathrm{~m}$ & \\
& & \\
\end{tabular}

PARAMETROS DA BOMBA

\begin{tabular}{l|c|c}
\hline \multicolumn{1}{c|}{ Dados obtidos } & Resultados & Observaçöes \\
\hline Altura manométrica total do sistema: & $18,47 \mathrm{~m}$ & \\
Rendimento da bomba & $45 \%$ & Rendimento indicado pelo usuário para cálculo da potência \\
Potência no eixo da bomba: & $2,19 \mathrm{CV}$ & Poténcia calculada para a bomba, sem fator de reserva \\
N.P.S.H Disponivel: & $12,4988 \mathrm{~m}$ & O N.P.S.H disponivel deve ser $>=$ N.P.S.H requerido \\
\hline
\end{tabular}

Figura 14. Relatório Final do Software

\section{CONCLUSÃO}

- O software, se mostrou muito prático, simples e de fácil utilização, realizando todas as operações necessárias para um resultado consistente ao final de todo o processo, dando ainda ao usuário a liberdade de escolha, a respeito do método a ser utilizado para dar seguimento nos cálculos das perdas de carga nas tubulações, apresentando ainda a comparação entre tais métodos.

- A maior vantagem observada é em relação ao tempo necessário para se efetuar os cálculos, quando comparados ao tempo que uma pessoa normalmente levaria, além disso, todos os passos possuem verificações, para assegurar que os dados informados são coerentes e que as restrições impostas por cada equação estão sendo respeitadas, dando assim ganhos em tempo e consistência dos dados obtidos. Somase a isso, o fato da presença de dicas, "hints", que auxiliam em caso de dúvidas assim como áreas de ajuda.

\section{REFERÊNCIAS BIBLIOGRÁFICAS}

BORBA, M.M.Z. Agricultura, Computador e internet: um estudo na região agrícola de Jaboticabal/SP. In: Congresso da Sociedade 
Brasileira de Economia e Sociologia Rural, 2004, Cuiabá/MT. Anais do XLII Congresso da Sociedade Brasileira de Economia e Sociologia Rural, 2004. p. 168-168 Disponível em: $<$ http://www.sober.org. br/palestra/12/02P147.pdf $>$. Acesso em: $18 \mathrm{fev}$. 2016.

HONDA, B.; JORGE, L.A.C. Computação aplicada a agricultura de precisão. Revista Científica Eletrônica UNISEB. Ribeira Preto, v.1, n.1, 2013.

MARQUES, P.A.M.; Modelo computacional para determinação do risco econômico em culturas irrigadas. 2005. Piracicaba. 217f. Tese (Doutorado em Agronomia) - Escola Superior de Agricultura, Universidade de São Paulo, Piracicaba. 2005.

MERCANTE, E.; SOUZA, E.G.; JOHANN, J.A.; GABRIEL FILHO, A.; URIBE-OPAZO, M.A. PRAPRAG - Software para planejamento racional de máquinas agrícolas. Engenharia Agrícola: Jaboticabal, v.30, n.2, 2010.

PORTO, R.M. Hidráulica Básica. São Carlos: EdUSP, $4^{\circ}$ ed, 517p. 2006.

PIACENTINI, L.; SOUZA, E.G.; URIBE-OPAZO, M.A.; NÓBREGA, L.H.P.; MILAN, M. Software para custo operacional de máquinas agrícolas - MAQCONTROL. Engenharia Agrícola,
Jaboticabal, v.32, n.3, 2012.

ROMANI, L.A.S.; MAGALHAES, G.B.; EVANGELISTA, S.R.M. Desenvolvimento de aplicativos móveis em agricultura: Agritempo mobile. Anais: X Congresso Brasileiro de Agroinformática, Campinas, 2015. Disponível em: $<$ https://www.embrapa.br/busca-de-publicacoes/-/ publicacao/1027337/desenvolvimento-deaplicativos-moveis-em-agricultura-agritempo$\underline{\text { mobile> }}$. Acesso em: 09 set. 2016.

SANTOS, J.P.F. Desenvolvendo Aplicativos com Lazarus. São Paulo, $1^{\circ}$ ed, 2011.

SWAMEE, P.K.; JAIN, A.K. Explicit equations for pipe-flow problems. Journal of Hydraulics Division, New York, v.102, n.5, 1976.

VALENTE, D.S.M.; QUEIROZ, D.M.; SILVA, L.C.; OLIVEIRA, G. H. H.; SANTOS, F.L. .LINSEC - Programa computacional para modelagem e simulação de sistemas de secagem de grãos. Revista Ciência Agronômica, Fortaleza, v.43, n.4, 2012.

ZANETTI, S.S.; PRUSKI, F.F.; MOREIRA, M.C.; SEDIYAMA, G.C.; SILVA, D.D. Programa computacional para geração de séries sintéticas de precipitação. Engenharia Agrícola, Jaboticabal, v.25, n.1, 2005. 